\title{
Effect of octreotide and insulin on manifest renal and glomerular hypertrophy and urinary albumin excretion in long-term experimental diabetes in rats
}

\author{
H. Grønbæk ${ }^{1}$, B. Nielsen ${ }^{1}$, R. Østerby ${ }^{2}$, A. Harris ${ }^{3}$, H. Ørskov ${ }^{1}$, A. Flyvbjerg ${ }^{1}$ \\ ${ }^{1}$ Institute of Experimental Clinical Research, Aarhus Kommunehospital, Aarhus, Denmark \\ ${ }^{2}$ Electron Microscopical Diabetes Research Laboratory, University Institute of Pathology, Aarhus Kommunehospital, \\ Aarhus, Denmark \\ ${ }^{3}$ Division of Clinical Pharmacology, Cedars-Sinai Medical Center, Los Angeles, California, USA
}

\begin{abstract}
Summary Treatment of diabetic rats with octreotide can inhibit early diabetic renal hypertrophy. Octreotide administration for 6 months from the day of diabetes induction inhibits renal hypertrophy and diminishes increase in urinary albumin excretion. To investigate the effect of octreotide on manifest diabetic renal changes, octreotide treatment was given for 3 weeks after an untreated diabetic period of 3 or 6 months. In addition, following 6 months of diabetes, a group of diabetic rats was treated with insulin for 3 weeks. Renal and glomerular hypertrophy, and increased urinary albumin excretion were observed in diabetic rats compared to non-diabetic control rats from 3 months and throughout the study period. Octreotide treatment did not affect body weight, food intake, blood glucose or serum fructosamine levels. We observed no effect of octreotide treatment on renal and glomerular hypertrophy or urinary albumin excretion compared to placebo-
\end{abstract}

treated diabetic rats. Insulin treatment for 3 weeks after 6 months of untreated diabetes normalized blood glucose and serum fructosamine levels, and furthermore renal hypertrophy was significantly diminished compared to the placebo-treated diabetic rats. However, insulin treatment had no effect on glomerular hypertrophy or urinary albumin excretion. In conclusion, octreotide treatment for 3 weeks following an untreated diabetic period of 3 or 6 months is unable to reduce the increased renal and glomerular volume or urinary albumin excretion. However, insulin treatment for 3 weeks with induction of euglycaemia diminishes the renal hypertrophy but has no effect on glomerular volume or urinary albumin excretion. [Diabetologia (1995) 38: 135-144]

Key words Diabetes mellitus, octreotide, urinary albumin excretion, renal hypertrophy, kidney morphology, IGF-I, IGFBPs, rat.
In early human and experimental diabetes mellitus an increase in kidney size and function is observed within the first weeks after onset of diabetes [1-3]. The initial renal hypertrophy and hyperfiltration have been proposed to be associated with the later

Received: 17 May 1994 and in revised form: 10 August 1994

Corresponding author: Dr. H. Grønbæk, Institute of Experimental Clinical Research, M-Lab II, Aarhus Kommunehospital, DK-8000 Aarhus C, Denmark

Abbreviations: UAE, Urinary albumin excretion; IGF-I, insulin-like growth factor I; IGFBP, insulin-like growth factor binding protein; STZ, streptozotocin; TGV, total glomerular volume; BW, body weight; GH, growth hormone; RPF, renal plasma flow. development of long-term diabetic renal damage and increased urinary albumin excretion (UAE) [47]. The precise mechanism responsible for the initial kidney hypertrophy-hyperfunction syndrome has not yet been revealed, though a number of experimental and clinical studies has been designed and conducted to clarify this issue. Recent results indicated a possible role for the insulin-like growth factor I (IGF-I) as an early renotropic factor in experimental diabetes, since kidney IGF-I increases and reaches a peak $24-48 \mathrm{~h}$ after diabetes induction and thus precedes the renal and glomerular hypertrophy [8-11]. IGF-I is bound to IGF binding proteins (IGFBPs) of which six are known today (IGFBP-1 to -6), these IGFBPs may function as carriers and/or modulators of IGF-I activity $[12,13]$. A recent study demonstrat- 
ed a transient increase in kidney IGFBP-1 and/or IGFBP-2, and IGFBP-3 in early experimental diabetes simultaneously with the kidney IGF-I increase [14]. Whether IGF-I and the IGFBPs are involved in the maintenance of the renal hypertrophy-hyperfunction syndrome with increased UAE is at present unknown.

In previous studies in experimental diabetes, treatment with insulin and the somatostatin analogue, octreotide, prevented the initial renal hypertrophy when administered during the first 7 days of diabetes [8]. Further, octreotide treatment of diabetic rats for 6 months, initiated on the day of diabetes induction, inhibited the kidney hypertrophy as well as the increase in UAE without affecting the metabolic control of the rats [15]. In a clinical study octreotide administration for 12 weeks to insulin-dependent diabetic (IDDM) patients induced similar results, i.e. a decrease in kidney size and glomerular filtration rate without changes in the glycaemic control [16].

The aim of the present study was to investigate and compare the effect of octreotide and insulin treatment for 3 weeks, initiated when diabetic renal changes are already manifest following 3 and 6 months of experimental diabetes, respectively. Objective parameters were renal and glomerular size, UAE, serum and kidney IGF-I and IGFBPs.

\section{Materials and methods}

Animals. Adult female Wistar rats (Møllegaards Avlslab, Eiby, Denmark) with a mean body weight of $197 \pm 1.0 \mathrm{~g}$ at the start of the experiment were studied. Rats were housed two to three per cage in a room with $12: 12 \mathrm{~h}(06.30-18.30$ hours) artificial light cycle, temperature $21 \pm 2{ }^{\circ} \mathrm{C}$ and humidity $55 \pm 2 \%$. The animals had free access to standard rat chow (Altromin, Lage, Germany) and tap water throughout the experiment. Animals were randomized into four groups matched for body weight (BW): 1) non-diabetic control rats $(n=40) ; 2)$ diabetic rats, placebo treated $(n=32) ; 3$ ) diabetic rats, octreotide treated $(n=24)$, and 4$)$ diabetic animals treated with insulin $(n=8)$. Non-diabetic control rats were investigated on day 0 , after 3 months $(3 \mathrm{~m}), 3$ months +3 weeks $(3 m+3 w)$, after 6 months $(6 m)$, and 6 months +3 weeks $(6 m+3 w)$, eight rats each day. Diabetic rats treated with placebo were examined after $3 m, 3 m+3 w, 6 m$, and $6 m+3 w$, eight rats each day. Diabetic rats treated with octreotide were investigated after $3 m+3 w$ and $6 m+3 w, 12$ rats each day. Insulin-treated diabetic rats were investigated at the end of the study after 6 months +3 weeks of insulin treatment.

Diabetes was induced on day 0 by i.v. injection of streptozotocin (STZ) $(55 \mathrm{mg} / \mathrm{kg}$ body weight) in acidic $0.154 \mathrm{~mol} / 1$ $\mathrm{NaCl}$ ( $\mathrm{pH} 4.5$ ) following $12 \mathrm{~h}$ of food deprivation. Three days after administration of STZ the animals were weighed, urinalysis was performed for glucose and ketones using Neostix 4 (Ames Limited, Stoke Poges, Slough, UK) and tail-vein blood glucose determined by Haemoglucotest 1-44 and Reflolux II reflectance meter (Boehringer-Mannheim, Mannheim, Germany). Animals were excluded from the study by the presence of ketonuria, blood glucose levels below $17 \mathrm{mmol} / \mathrm{l}$ or the presence of pyelonephritis. The body weight, urine and tail blood analyses as well as food intake were measured monthly during the 6-month study period and every $2-3$ days during the 3 weeks of octreotide or insulin treatment. Animals were housed individually in metabolic cages for 24-h urine collections for determination of albumin excretion. This was performed by the start of the experiment and at the start and end of the two 3-week periods of octreotide and insulin treatment following a diabetes duration of 3 and 6 months, respectively. Octreotide was dissolved in acetic acid buffer $50 \mathrm{mmol} / 1, \mathrm{pH} 4.9(500 \mu \mathrm{g} / \mathrm{ml})$, and octreotide-treated diabetic rats were injected subcutaneously twice daily $(200 \mu \mathrm{g} / 24 \mathrm{~h})$ in order to achieve high enough diurnal serum levels to inhibit endogenous growth hormone $(\mathrm{GH})$ and IGF-I production [9, 15]. Octreotide treatment for 3 weeks was initiated after 3 months and 6 months, respectively and only in animals having manifest diabetes. During the same period placebo-treated diabetic rats were treated with twice-daily injections of the vehicle of acetic acid buffer as were non-diabetic control rats. Following 6 months of diabetes, a group of diabetic animals started insulin treatment in order to normalize blood glucose levels. Subcutaneous injections with a bovine very-longacting heat treated Ultralente Insulin (Novo, Gentofte, Denmark) were given twice daily to achieve euglycaemia.

On the day of termination the animals were anaesthetized with sodium barbital (50 $\mathrm{mg} / \mathrm{kg} \mathrm{BW}$ ) and rapidly dissected to obtain the kidneys following eye blood puncture. The right kidneys were weighed and immediately frozen in liquid nitrogen and stored at $-80^{\circ} \mathrm{C}$ until further analysis. The left kidneys were gently stripped of their capsules, weighed, and fixed in $3 \%$ formaldehyde and $1 \%$ glutaraldehyde in modified Tyrode buffer overnight [17]. The fixed kidneys were then cut into 2-mm thick slices by a set of spaced razor blades and embedded in paraffin. Sections were prepared from the "righthand cut side" of each slide at two different levels with a distance of $250 \mu \mathrm{m}$ followed by Periodic acid-Schiff (PAS)-staining. This provided a set of randomly-positioned equidistantly-

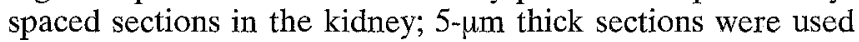
for standard stereological measurements $[18,19]$ (see below).

\section{Determination of metabolic parameters}

Blood glucose. Blood glucose was measured in tail-vein blood by Haemoglucotest 1-44 and Reflolux II reflectance meter (Boehringer-Mannheim).

Determination of fructosamine. Reagents and standards for the fructosamine assay, Fructosamine Test Plus, were purchased from Hoffmann-La Roche (Basle, Switzerland) and the determination performed as previously described [20]. All serum samples were measured at the end of the study after storage at $-80^{\circ} \mathrm{C}$ in order to avoid interassay variation.

Urinary albumin excretion (UAE). The urinary albumin concentration in 24-h urine collections was determined by radioimmunoassay as previously described [21] using rat albumin antibody and standards. The urine samples were stored at $-80^{\circ} \mathrm{C}$ until assay was performed. Rabbit anti-rat albumin antibody RARa/Alb was purchased from Nordic Pharmaceuticals and Diagnostics (Tilburg, The Netherlands). For standard and iodination a globulin-free rat albumin was obtained from Sigma Chemical Co. (St.Louis, Mo., USA). 


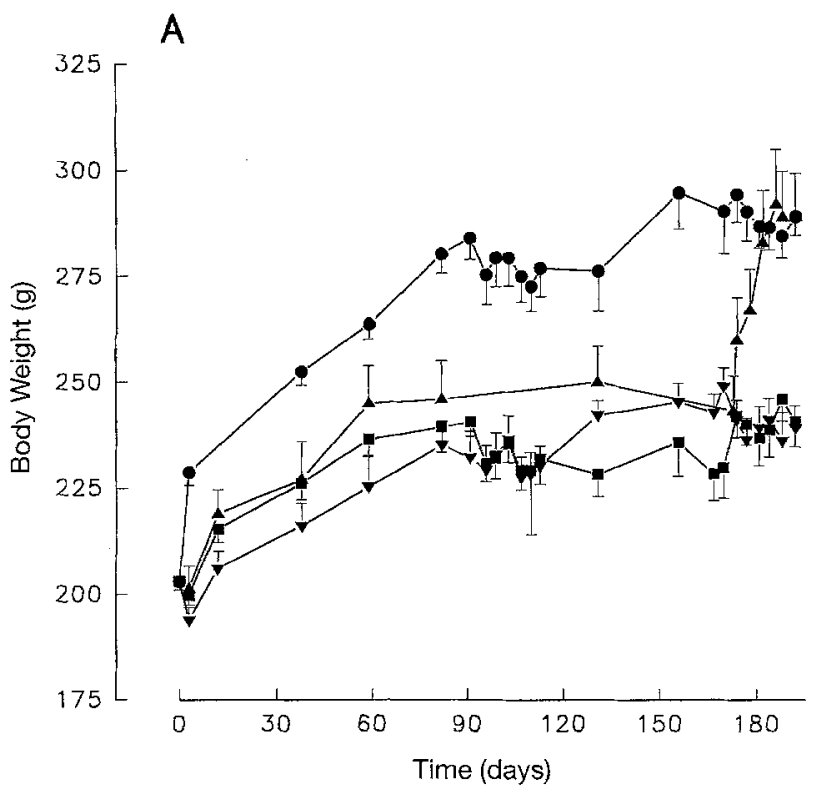

B

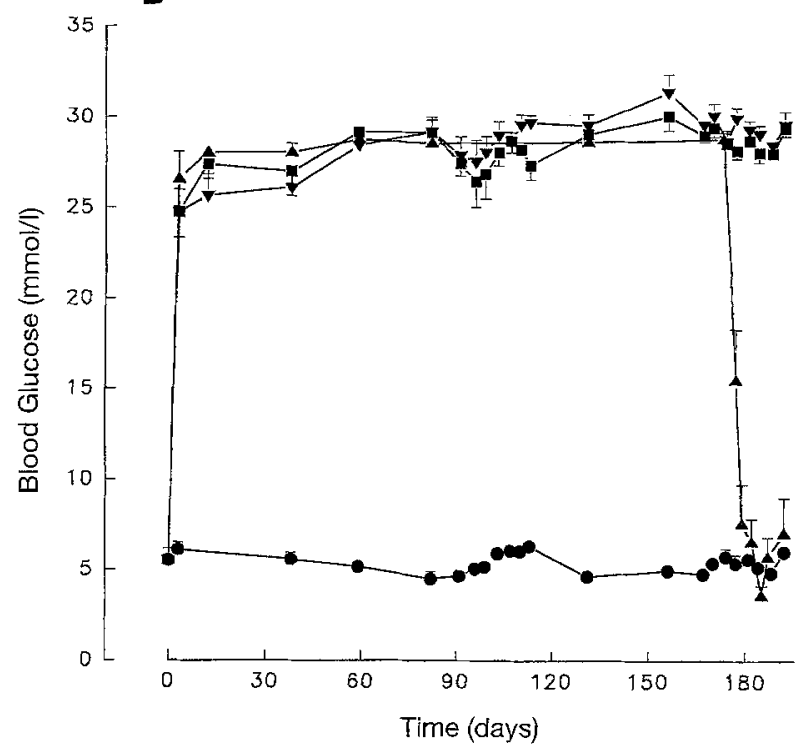

C

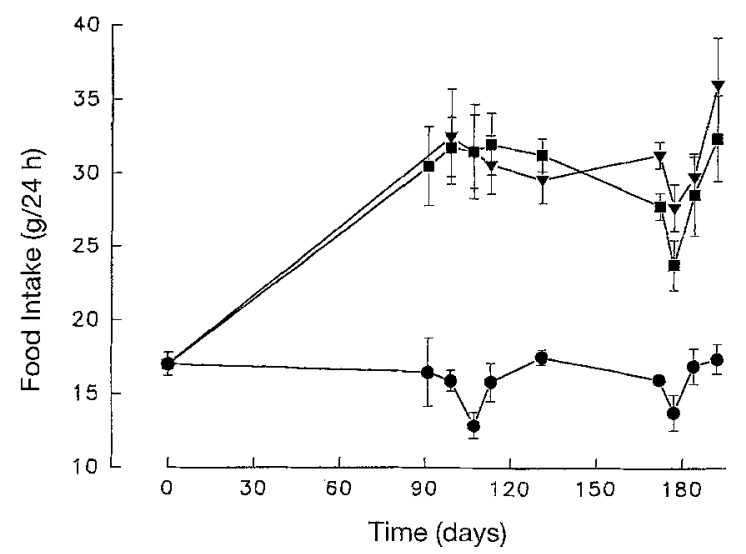

Fig. 1 (A-C). Changes in (A) body weight; (B) blood glucose levels; (C) 24-h food consumption in the experimental groups during the study period. Non-diabetic control rats $(\bullet)$; diabetic placebo-treated rats $(\boldsymbol{\square})$; diabetic octreotide-treated $(\boldsymbol{\nabla})$, and insulin-treated diabetic rats $(\boldsymbol{\Delta})$. Values are mean \pm SEM

\section{Kidney and serum IGF-I measurements}

IGF-I extractions from kidney and serum, and IGF-I radioimmunoassay. Kidney IGF-I extraction was performed according to D'Ercole et al. [22]. Briefly, the kidneys were homogenized on ice in $1 \mathrm{~mol} / \mathrm{l}$ acetic acid ( $5 \mathrm{ml} / \mathrm{g}$ kidney) with an Ultra Turrax TD 25 (Janke-Kunkel GmbH, Stauten, Germany) and further disrupted using a Potter-Elvehjelm homogenizer. The tissues were extracted twice, and, after lyophilization, the samples were redissolved in $40 \mathrm{mmol} / \mathrm{l}$ phosphate buffer $(\mathrm{pH}=8.0$ ) with $0.2 \%$ BSA (Sigma Chemical Co.). Tissue extracts were kept at $-80^{\circ} \mathrm{C}$ until IGF-I assay was performed within 2 to 3 weeks after extraction. Serum IGF-I was extracted from the IGFBPs by HCl-ethanol. IGF-I was estimated using a polyclonal (rabbit) IGF-I antibody (Nichols Institute Diagnostics, San Juan Capistrano, Calif., USA) obtained from SMS-Gruppen, Hørsholm, Denmark. For standards $(0.312-20 \mu \mathrm{g} / \mathrm{l})$ a full amino acid sequence analogue (Amgen Biologicals, Thousand Oaks, Calif., USA) was purchased from Amersham (Bucks., UK) and ${ }^{125}$ I labelled IGF-I was donated by Novo (Bagsværd, Denmark). All constituents were made up in $40 \mathrm{mmol} / \mathrm{l}$ phosphate buffer, $\mathrm{pH} 8.0$, with $5 \%$ human serum albumin (Beringwerke AG, Marburg, Germany) and sodium merthiolate $0.6 \mathrm{mmol} / \mathrm{l}$. Standard, diluted kidney extract or sera, $(25 \mu \mathrm{l})$, ${ }^{125}$ I-IGF-I, $(50 \mu \mathrm{l})$, and anti-IGF-I, $(50 \mu \mathrm{l})$, were incubated for $48 \mathrm{~h}$ at $4^{\circ} \mathrm{C}$, after which was added $50 \mu \mathrm{l}$ porcine gamma globulin $1 \%$ (Sigma Chemical Co.) and immediately thereafter $900 \mu \mathrm{l} 20 \%$ polyethylene glycol 6000 with $0.5 \%$ Tween 20 (Both from Merck, Darmstadt, Germany). Following centrifugation $\left(3000 \mathrm{rev} / \mathrm{min}\right.$ for $10 \mathrm{~min}$ at $\left.4{ }^{\circ} \mathrm{C}\right)$, supernatants were decanted, free and antibody-bound activities were counted in order to determine binding percentage. Linearity was observed for multiple dilutions of extracted serum and kidney IGF-I indicating that no IGFBPs interfere in the assay. IGF-I recovery in serum was estimated to $109 \pm 7 \%$ (SEM). Intraassay coefficient of variation was $5.4 \%$ and interassay was $9.3 \%$.

\section{IGF binding proteins}

SDS-PAGE and Western ligand blot analysis of IGFBPS. SDSPAGE and Western ligand blot analysis were performed according to the method of Hossenlopp et al. [23] as previously described [14]. Autoradiographs of ligand blots were scanned using a laser densitometer (Shimadzu Corporation, Kyoto, Japan). The relative densities of the band were measured as arbitrary absorbency units per $\mathrm{mm}^{2}\left(\mathrm{AU} / \mathrm{mm}^{2}\right)$.

\section{Kidney morphology}

Glomerular volume fraction and total glomerular volume per kidney were estimated in animals examined at day 0 and at the end of the two 3 week treatment periods following 3 $(3 m+3 w)$ and 6 months $(6 m+3 w)$ diabetes (non-diabetic controls $n=6$; diabetes-placebo $n=8$; diabetes-octreotide $n=8$; diabetes-insulin $n=7$ ). Estimation of glomerular volume fraction and total glomerular volume was performed as previously described [24].

\section{Statistical analysis}

All results are given as mean values \pm SEM. Differences between groups were analysed by one-way analysis of variance (ANOVA) in combination with the Bonferroni test for multi- 
Table 1. Serum fructosamine levels measured in the different experimental groups during the study period

\begin{tabular}{lllll}
\hline Days in experiment & $\begin{array}{l}\text { Non-diabetic } \\
\text { controls }\end{array}$ & $\begin{array}{l}\text { Diabetes } \\
\text { placebo }\end{array}$ & $\begin{array}{l}\text { Diabetes } \\
\text { octreotide }\end{array}$ & $\begin{array}{l}\text { Diabetes } \\
\text { insulin }\end{array}$ \\
\cline { 2 - 5 } & $\mu \mathrm{mol} /$ litre & & & \\
\hline Day 3 months & $198 \pm 12^{\mathrm{a}}$ & $259 \pm 21$ & \\
Day 3 months + 3 weeks & $191 \pm 9^{\mathrm{b}}$ & $242 \pm 16$ & $243 \pm 20$ & \\
Day 6 months & $183 \pm 20^{\mathrm{a}}$ & $243 \pm 18$ & $247 \pm 7$ & $204 \pm 6^{\mathrm{d}}$ \\
\hline Day 6 months + 3 weeks & $188 \pm 12^{\mathrm{c}}$ & $253 \pm 20$ & 248 \\
\hline
\end{tabular}

Values are mean \pm SEM. ${ }^{a} p<0.05$ compared to diabetic animals day $3 \mathrm{~m}$ or $6 \mathrm{~m} .{ }^{\mathrm{b}} p<0.05$ compared to octreotide- and placebo-treated diabetic animals day $3 m+3 w .{ }^{c} p<0.01$

ple comparisons and unpaired Student's $t$-test for unpaired samples. Kruskal-Wallis non-parametric ANOVA test was used on measurements of UAE. $p<0.05$ was considered statistically significant in a two-tailed test.

\section{Results}

\section{Metabolic parameters}

Body weight. Body weight changes observed during the study period in the four experimental groups are shown in Figure 1A. Diabetes induction was followed by a small body weight loss with a nadir on day 2-3; however, the diabetic rats started regaining weight and had a significant body weight gain throughout the study period $(p<0.05)$. The diabetic rats grew more slowly compared to the non-diabetic control rats $(p<0.05)$. Following 3 and 6 months of diabetes duration the diabetic groups had identical body weights before treatment with octreotide or placebo was initiated. Octreotide treatment for 3 weeks after 3 and 6 months of diabetes did not alter body weight. However, the group treated with insulin following 6 months of diabetes exhibited a rapid weight increase achieving identical body weights compared to the non-diabetic control rats at the end of the 3week insulin treatment period.

Blood glucose. Blood glucose values measured in all animals during the experimental period are shown in Figure 1B. All animals given STZ developed hyperglycaemia with mean blood glucose concentrations around $25 \mathrm{mmol} / 1$ and remained at that level for the duration of the study. Octreotide treatment of the diabetic rats did not influence blood glucose levels when compared to placebo-treated diabetic animals. All diabetic animals had glycosuria greater than $111 \mathrm{mmol} / \mathrm{l}$ and none of the animals exhibited ketonuria at any time during the study period. The rats treated with insulin for 3 weeks showed a normalization of blood glucose values and absence of glycosuria.

Serum fructosamine. Table 1 shows the serum fructosamine levels observed in the different experimental groups throughout the study period. Following 3 and compared to octreotide- and placebo-treated rats. ${ }^{\mathrm{d}} p<0.05$ compared to octreotide- and placebo-treated animals

6 months of diabetes duration the placebo-treated rats had significantly higher serum fructosamine levels compared to the non-diabetic control rats $(p<0.05)$. By the end of the two 3-week octreotide treatment periods, following 3 and 6 months of untreated diabetes, no effect of octreotide on serum fructosamine levels was observed compared to placebotreated diabetic rats $(p<0.05)$. However, both diabetic groups had significantly higher levels compared to the non-diabetic control rats $(p<0.05)$. Insulin treatment for 3 weeks following 6 months of diabetes resulted in normalization of serum fructosamine levels.

Food intake. Food consumption over $24 \mathrm{~h}$ was measured during the study period on a group basis (twothree rats) and is shown Figure 1C. Values are a mean of food intake per rat in the cage and given as gram fodder per $24 \mathrm{~h}$ per rat. The diabetic animals were characterized by hyperphagia eating on the average $90 \%$ more than the non-diabetic control animals $(p<0.05)$. During the two 3-week periods of octreotide treatment following 3 and 6 months of diabetes duration, no change in food intake was observed compared to the placebo-treated diabetic animals. The insulin-treated diabetic rats exhibited a similar degree of hyperphagia during the catch-up growth and normalization of blood glucose levels.

Kidney weight. Figure 2 shows the kidney weights in the experimental groups. Diabetic renal hypertrophy was present after 3 months of diabetes equivalent to an increase compared to non-diabetic controls of $42.5 \%$ (1100 $\pm 14 \mathrm{mg}$ vs $772 \pm 23 \mathrm{mg}, p<0.0001)$; and a similar $45.8 \%$ increase was observed after 6 months of diabetes $(1059 \pm 46 \mathrm{mg}$ vs $773 \pm 33 \mathrm{mg}$, $p<0.0001$ ). Octreotide treatment for 3 weeks following 3 and 6 months of diabetes did not significantly reduce the degree of renal hypertrophy, however, a trend towards lower kidney weights compared to the placebo-treated diabetic animals was observed $(0.05<p<0.10)$. The rats treated with insulin for 3 weeks following 6 months of diabetes exhibited a significant decrease in kidney weight of $15.7 \%$ compared to the placebo-treated diabetic rats $(982 \pm 38$ $\mathrm{mg}$ vs $1166 \pm 33 \mathrm{mg}, p<0.01)$. The kidney weights 


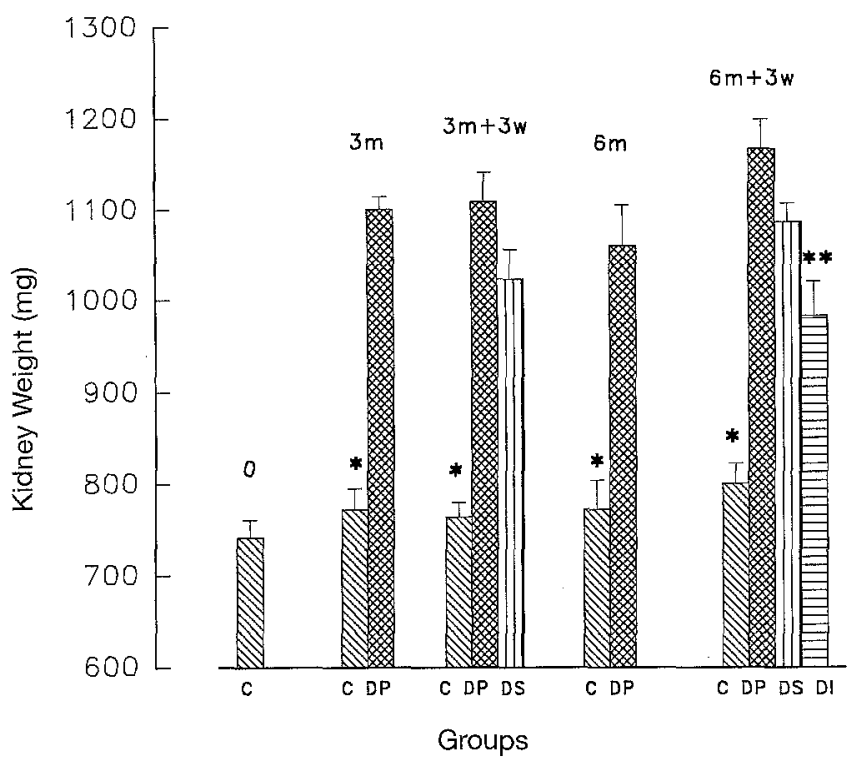

Fig. 2. Kidney weights observed in the individual groups throughout the experimental period. Non-diabetic control rats (C); diabetic placebo-treated rats (DP); diabetic octreotide-treated (DS), and insulin-treated diabetic rats (DI). Values are mean $\pm \mathrm{SEM}$. ${ }^{*} p<0.0001$ compared to placebotreated diabetic rats examined the same day. $* * p<0.01 \mathrm{com}-$ pared to the placebo-treated diabetic rats by the end of the study

from insulin-treated rats were still significantly higher compared to the non-diabetic control rats $(p<0.01)$.

Kidney IGF-I. Kidney IGF-I levels in the different experimental groups are shown in Table 2. We ob- served a decrease in kidney IGF-I levels with increasing age in the non-diabetic control rats during the experimental period $(p<0.05)$. Following 3 months of diabetes significantly lower renal IGF-I levels were observed in both diabetic groups compared to the non-diabetic control rats $(p<0.01)$. After 6 months +3 weeks following treatment with either placebo, octreotide or insulin no difference was observed between any of the four groups (NS).

Kidney morphology. Glomerular volume fraction $\left(\mathrm{V}_{\mathrm{v}}\right)$ and total glomerular volume (TGV) in kidneys from non-diabetic control animals and diabetic animals treated with octreotide, placebo or insulin for 3 weeks following 3 or 6 months of diabetes duration are shown in Table 3. A significant age-dependent increase in $\mathrm{V}_{\mathrm{v}}$ and $\mathrm{TGV}$ was observed in the non-diabetic control animals $(p<0.05)$. Following a diabetic period of $3 m+3 w$, the octreotide and placebo-treated diabetic rats had significantly smaller $\mathrm{V}_{\mathrm{v}}$ compared to the non-diabetic control rats $(p<0.05)$. Further, there was no effect of octreotide treatment since $V_{v}$ in this group was identical to the level observed in the placebo-treated diabetic group. After $6 m+3 w$ no difference was observed in $V_{v}$ between any of the groups. Diabetes induction implied a significant increase in TGV throughout the study period, being significantly higher compared to the nondiabetic control rats at the end of the study $(p<0.05)$, but not after 3 months $(p>0.05)$. We observed no effect of octreotide on TGV following 3 or 6 months of diabetes duration compared to the place-

Table 2. Kidney IGF-I extracted from kidneys in the animals investigated throughout the study period

\begin{tabular}{|c|c|c|c|c|}
\hline \multirow[t]{2}{*}{ Days in experiment } & $\begin{array}{l}\text { Non-diabetic } \\
\text { controls }\end{array}$ & $\begin{array}{l}\text { Diabetes } \\
\text { placebo }\end{array}$ & $\begin{array}{l}\text { Diabetes } \\
\text { octreotide }\end{array}$ & $\begin{array}{l}\text { Diabetes } \\
\text { insulin }\end{array}$ \\
\hline & \multicolumn{4}{|c|}{ ng IGF-I per gram kidney weight } \\
\hline Day 3 months & $306 \pm 33$ & $314 \pm 39$ & & \\
\hline Day 3 months +3 weeks & $290 \pm 25^{b}$ & $202 \pm 14$ & $195 \pm 13$ & \\
\hline Day 6 months & $254 \pm 32$ & $227 \pm 13$ & & \\
\hline
\end{tabular}

Values are mean \pm SEM. ${ }^{\mathrm{a}} p<0.05$ compared to control rats at the end of the study. ${ }^{\mathrm{b}} p<0.01$ compared to diabetic placebo- or octreotide-treated rats

Table 3. Glomerular volume fraction $\left(\mathrm{V}_{\mathrm{V}}, \% / \mathrm{kidney}\right)$ and total glomerular volume (TGV, $\mathrm{mm}^{3} /$ kidney) in kidneys from nondiabetic control rats and diabetic rats treated with octreotide,

\begin{tabular}{|c|c|c|c|c|c|}
\hline Days in study & & $\begin{array}{l}\text { Non-diabetic } \\
\text { controls }\end{array}$ & $\begin{array}{l}\text { Diabetes- } \\
\text { placebo }\end{array}$ & $\begin{array}{l}\text { Diabetes- } \\
\text { octreotide }\end{array}$ & $\begin{array}{l}\text { Diabetes- } \\
\text { insulin }\end{array}$ \\
\hline 0 & $\begin{array}{l}\mathrm{V}_{\mathrm{V}} \\
\mathrm{TGV}\end{array}$ & $\begin{array}{r}2.54 \pm 0.14^{\mathrm{a}} \\
18.45 \pm 1.19^{\mathrm{a}}\end{array}$ & & & \\
\hline $3 m+3 w$ & $\begin{array}{l}\mathrm{V}_{\mathrm{V}} \\
\mathrm{TGV}\end{array}$ & $\begin{array}{c}3.39 \pm 0.10^{\mathrm{b}} \\
24.73 \pm 1.24\end{array}$ & $\begin{array}{r}2.72 \pm 0.22 \\
27.82 \pm 1.53\end{array}$ & $\begin{array}{r}2.43 \pm 0.08 \\
24.56 \pm 1.01\end{array}$ & \\
\hline $6 m+6 w$ & $\begin{array}{l}\mathrm{V}_{\mathrm{V}} \\
\mathrm{TGV}\end{array}$ & $\begin{array}{c}3.25 \pm 0.10 \\
24.20 \pm 1.36^{\mathrm{c}}\end{array}$ & $\begin{array}{r}2.98 \pm 0.18 \\
33.77 \pm 2.40\end{array}$ & $\begin{array}{r}3.03 \pm 0.12 \\
31.47 \pm 1.05\end{array}$ & $\begin{array}{r}3.30 \pm 0.14 \\
30.49 \pm 1.62\end{array}$ \\
\hline
\end{tabular}

Values are mean \pm SEM. ${ }^{a} p<0.05$ compared to all other non-diabetic control rats; ${ }^{\mathrm{b}} p<0.05$ compared to all other groups investigated at day $3 \mathrm{~m}+3 \mathrm{w} ;{ }^{c} p<0.05$ compared to octretide- and placebo-treated rats after $6 \mathrm{~m}+3 \mathrm{w}$ placebo or insulin for 3 weeks after 3 months $(3 m+3 w)$ or 6 months $(6 m+3 w)$ of diabetes duration 


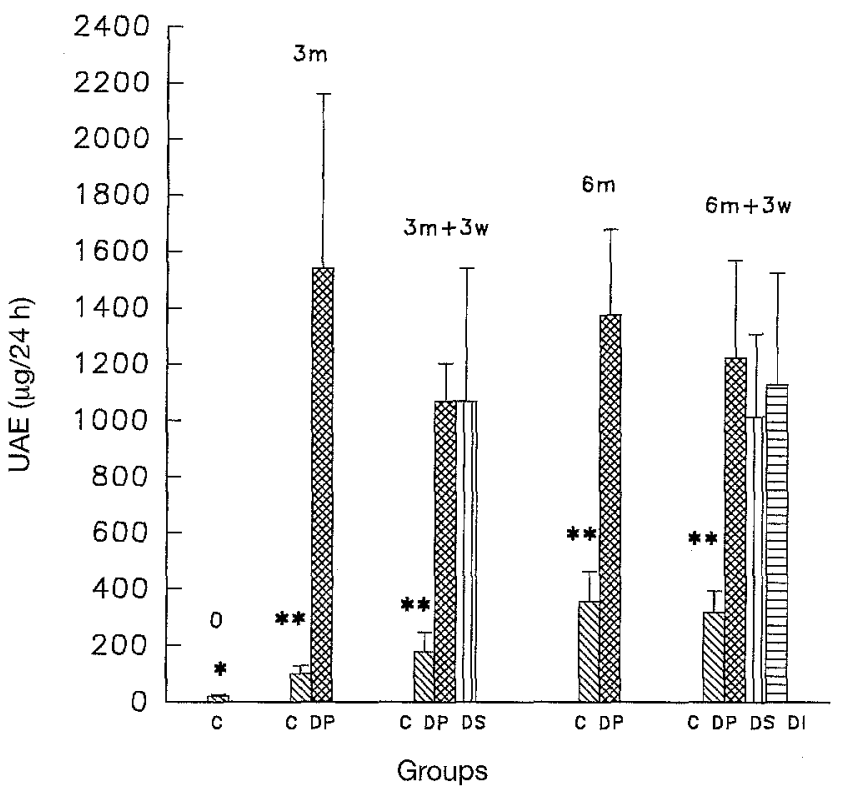

Fig. 3. Changes in urinary albumin excretion (UAE) during the study period in non-diabetic control animals (C), diabetic rats treated with placebo (DP), octreotide (DS) or insulin (DI). Values are mean \pm SEM. $* p<0.05$ compared to non-diabetic control rats by the end of the study period. $* * p<0.05$ compared to placebo-treated diabetic rats examined the same day

bo-treated diabetic rats (NS). The insulin-treated animals exhibited an insignificant change in TGV at the end of the study $(p<0.20)$.

Urinary albumin excretion. UAE measured throughout the study period is shown in Figure 3. The nondiabetic control rats exhibited an age-dependent increase in UAE having statistically higher UAE at the end of the study $(p<0.05)$. After 3 months of diabetes a significant increase in UAE was observed in the diabetic rats compared to control rats and still present after 6 months $(p<0.05)$. We observed no differences in UAE between octreotide and placebotreated diabetic animals following a diabetes duration of 3 or 6 months (NS). Similarly, insulin treatment for 3 weeks after 6 months of diabetes was not able to reduce UAE despite a normalization of the metabolic control.

Serum IGFBPs. In Western ligand blots of serum four distinct bands of IGFBPs were observed. The largest proportion is a doublet of $38-47 \mathrm{kDa}$ which corresponds to IGFBP-3 (Fig. 4A) followed by a $30 \mathrm{kDa}$ band representing IGFBP-1 and/or IGFBP-2 (Fig.4B) and a smaller fraction of $24 \mathrm{kDa}$ probably representing IGFBP-4 (Fig.4C). Diabetes induction had no significant effect on the band representing IGFBP-3; however, there was a tendency towards lower values of IGFBP-3 in all diabetic groups compared to the non-diabetic control rats. Octreotide treatment during the two 3 -week treatment periods
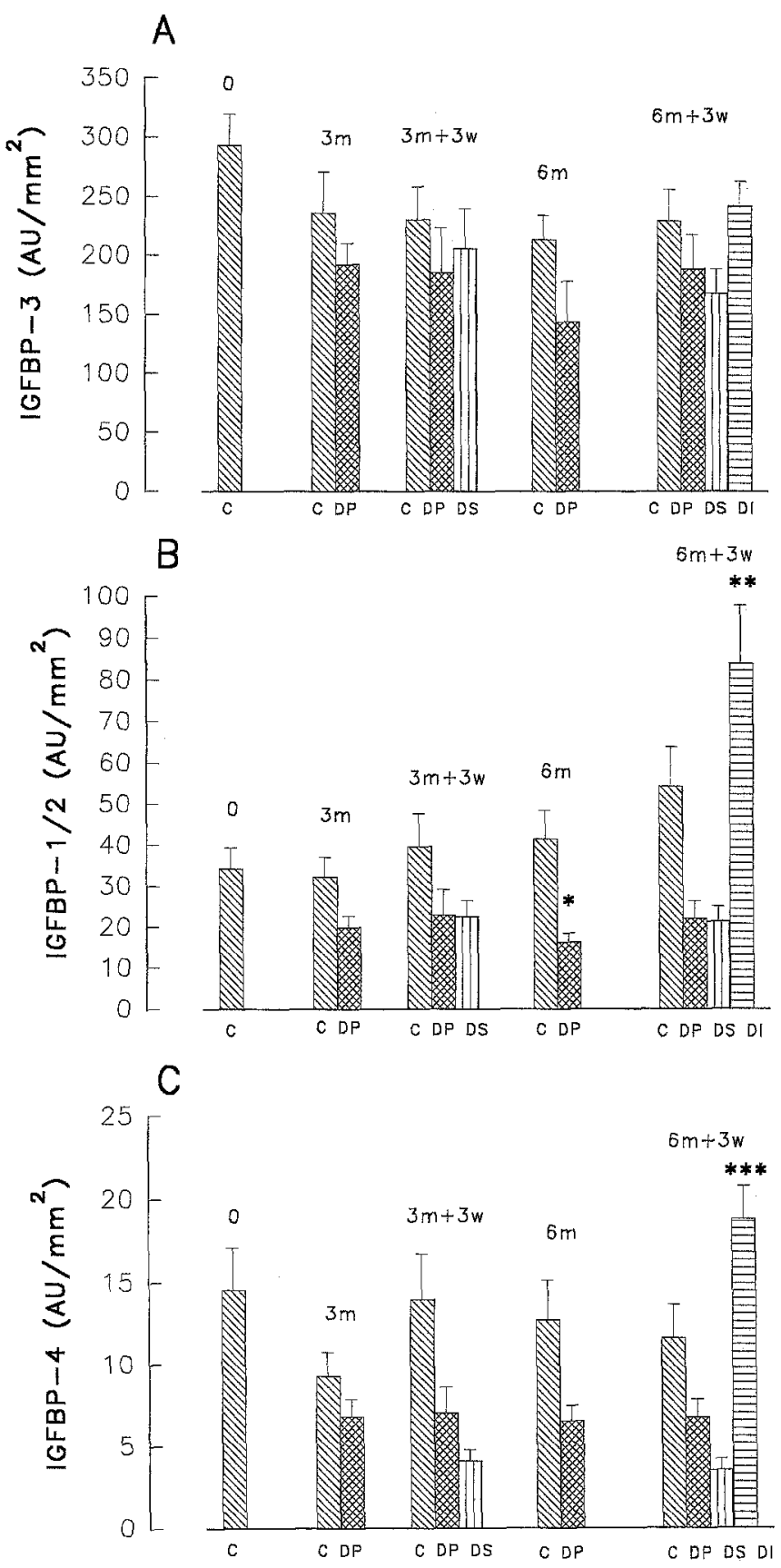

Fig. 4 (A-C). Serum IGF-binding proteins examined during the experimental period in non-diabetic control rats $(\mathbf{C})$; diabetic placebo treated rats (DP); diabetic octreotide-treated (DS), and insulin-treated diabetic rats (DI). Values are mean \pm SEM. (A) Changes in IGFBP-3 (AU, arbitrary units); (B) levels of IGFBP-1 and/or IGFBP-2. ${ }^{*} p<0.05$ compared to non-diabetic control rats the same day. $* * p<0.05 \mathrm{com}-$ pared to all other groups examined by the end of the study period. (C) Changes in IGFBP-4*** $p<0.05$ compared to all other groups examined by the end of the study period

had no effect on IGFBP-3 compared to placebotreated diabetic rats. Insulin treatment for 3 weeks following an untreated diabetes period of 6 months induced an increase in IGFBP-3 with levels higher than observed in the non-diabetic control rats (NS). 
Table 4. Serum IGF-I from non-diabetic control animals and diabetic animals investigated throughout the study period

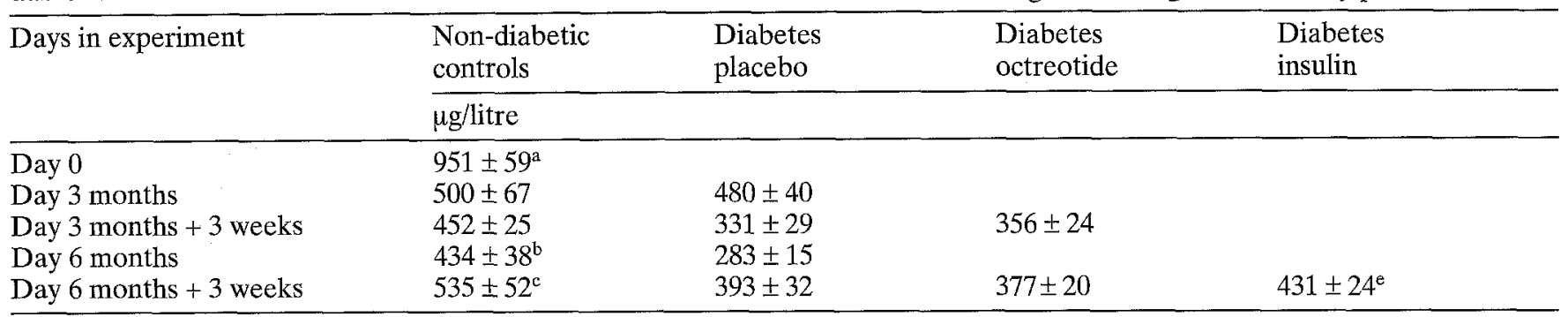

Values are mean \pm SEM. ${ }^{a} p<0.001$ compared to all other non-diabetic control groups; ${ }^{b} p<0.05$ compared to placebo-treated diabetic rats after $6 \mathrm{~m} ;{ }^{\mathrm{c}} p<0.05$ compared to placebo- and octreotide-treated diabetic rats at day $6 \mathrm{~m}+3 \mathrm{w}$ control animals

IGFBP-1 and IGFBP-2 have the same molecular weight in rats and are therefore represented by the same band. Diabetes induction was followed by a steady decrease in IGFBP-1 and/or IGFBP-2 compared to non-diabetic control animals, however, it was only significant after 6 months of diabetes $(p<0.05)$. Octreotide treatment for 3 weeks following 3 and 6 months of diabetes had no effect on the band representing these IGFBPs. However, insulin treatment for 3 weeks after 6 months of untreated diabetes with normalization of blood glucose levels was followed by a significant increase even exceeding the level observed in the non-diabetic control animals $(p<0.05)$. The band representing IGFBP-4 showed similar results; i.e. diabetes induction was followed by a decrease in IGFBP-4 compared to nondiabetic control rats. Octreotide treatment during the two 3-week treatment periods was followed by an insignificant reduction compared to placebo-treated diabetic rats. Insulin treatment for 3 weeks after 6 months of untreated diabetes duration was followed by a significant increase in the band representing IGFBP-4 compared to the non-diabetic control rats $(p<0.05)$.

Serum IGF-I. Serum IGF-I is shown in Table 4. An age-dependent decrease in total serum IGF-I was observed in the non-diabetic control rats during the study period. Diabetes induction was followed by a decrease in circulating IGF-I, though placebo-treated diabetic rats only had significantly lowerIGF-I levels compared to non-diabetic control rats after 6 months and at the end of the experiment $(p<0.01)$. We observed no effect of octreotide after the two 3-week treatment periods since octreotide and placebo-treated diabetic rats had identically decreased serum IGF-I levels compared to the non-diabetic control animals. Following insulin treatment for 3 weeks after 6 months of diabetes a normalisation of serum IGF-I was observed.

\section{Discussion}

In accordance with previous studies $[15,25]$ we have demonstrated an increase in kidney size, glomerular volume, and UAE after 3 and 6 months of diabetes. Octreotide treatment for 3 weeks after an untreated diabetes duration of 3 and 6 months did not influence the metabolic control of the rats since no changes were observed in blood glucose or serum fructosamine levels, body weight or food intake. Further, octreotide treatment of diabetic rats did not significantly affect renal and glomerular hypertrophy or UAE when compared to the placebo-treated diabetic rats. Insulin treatment for 3 weeks after 6 months of untreated diabetes, however, was followed by normalization of blood glucose and serum fructosamine levels, and restitution of body weight to the non-diabetic control level. We observed a significant reduction in kidney size in the insulin-treated rats, however, no effect of insulin treatment on UAE or TGV was observed compared to the placebo-treated diabetic rats.

Increasing interest in GH and IGF-I as mediators of renal hypertrophy and hyperfunction has emerged from the observation that IGF-I infusion in normal man and rats is followed by an acute increase in renal plasma flow (RPF) and glomerular filtration rate (GFR) [26, 27]. GH administration is more slowly followed by identical changes in RPF and GFR simultaneously with an increase in IGF-I levels indicating that the action of GH is mediated through IGF-I [28, 29]. Further, it has been shown that IGF-I treatment induces renal growth within days to weeks in various animal models [30-32]. As previously described IGF-I may play role as a renotropic factor in the development of early diabetic renal and glomerular hypertrophy [33]. The effect of somatostatin and its analogues, which are potential inhibitors of GH and IGF$\mathrm{I}$, has been examined in experimental and human diabetes during the past years. In early experimental diabetes, octreotide administration completely inhibits the initial renal hypertrophy through an inhibition of kidney IGF-I accumulation [9]; however, another study reported that only a partial inhibition of kidney IGF-I and growth took place [34], but the octreo- 
tide dose used in this experiment was smaller. As observed in these studies and also in the present study, octreotide has no effects on blood glucose levels in diabetic rats, indicating that the inhibition of kidney IGF-I accumulation and kidney growth is not caused by improved metabolic control. In long-term experimental diabetes, octreotide treatment for 6 months induced significant reductions in kidney weight and kidney IGF-I compared to untreated diabetic rats. UAE was reduced as well, whereas untreated diabetic rats showed progressive proteinuria and maintained renal hypertrophy [15]. These results have recently been confirmed using a lower octreotide dose during a diabetic period of 5 weeks, and in this study octreotide treatment also reduced glomerular hypertrophy [35]. A study with negative results has recently been published by Muntzel et al. [36] using a uninephrectomized-diabetic rat model. They observed no effect of octreotide on renal hypertrophy, UAE or glomerular hyperfiltration. However, they used a much smaller octreotide dose compared to Flyvbjerg et al. [15] and, further, they started octreotide treatment at the day of diabetes induction, 3 days after the nephrectomy had been performed. It has previously been shown that unilateral nephrectomy itself is followed by kidney IGF-I accumulation and growth of the remnant kidney [8] and, further, that diabetes induced in simultanously unilaterally nephrectomized rats gives an additive increase in kidney IGF-I accumulation and renal growth [10]. Octreotide treatment may either not have been sufficient to inhibit the IGF-I accumulation and renal growth caused by the additive stimulus, or the octreotide treatment [36] was initiated too late when the early IGF-I accumulation had already peaked due to nephrectomy. In the studies cited above $[9,15,34$, 35] octreotide treatment was initiated on the day of diabetes induction but only a single study has previously been conducted on octreotide intervention later in the diabetic period when renal pathological changes had become manifest. Igarashi et al. [37] treated uninephrectomized-diabetic rats with octreotide for 3 weeks after 15 weeks of untreated diabetes and observed diminished kidney hypertrophy and albuminuria. This is partly in contrast to the results of the present study in which we only find a trend towards diminished kidney weight and no effect on UAE. We suggest that further studies should be executed to estimate the critical dose and time of treatment initiation to achieve an effect.

Clinical renal studies of somatostatin and its analogues were initiated by Vora et al. [38], demonstrating an acute reduction in urinary flow, RPF, and GFR in insulin-dependent diabetic (IDDM) patients and non-diabetic control subjects following intravenous infusion of native somatostatin. Infusion of octreotide to IDDM patients induced an acute reduction in RPF and GFR, and in addition plasma GH and glucagon were decreased. The fall in glucagon concentration correlated significantly with the reduction in RPF and GFR [39], which is an interesting observation since glucagon may be involved in the diabetic renal hypertrophy-hyperfunction syndrome [40-42], though no conclusive results have been obtained [43]. In a long-term study octreotide administration for 12 weeks in IDDM patients caused a significant decrease in the elevated GFR, and total kidney volume was reduced as well. However, in this study no changes in plasma GH or glucagon levels were observed. Three of the patients were re-examined 12 weeks after cessation of octreotide treatment and their GFR had risen to the level at the start of the study [16]. In another study octreotide treatment induced a trend only towards lowering GFR [44].

Insulin treatment of STZ diabetic rats equally inhibits the local early diabetic kidney IGF-I accumulation and renal hypertrophy $[8,25]$. Furthermore, strict insulin treatment for 6 months initiated at the day of diabetes induction also diminishes the increase in UAE observed in poorly controlled diabetic rats [45]. When intensive insulin treatment for 7 weeks was initiated in poorly-controlled diabetic rats following 37 weeks of diabetes, a normalization of kidney weight and GFR was observed but there was no effect on glomerular mesangial volume [46]. However, in this study UAE was not examined. In the present study, we observed similar results following 3 weeks of insulin treatment after 6 months of untreated diabetes, i.e. diminished renal hypertrophy, and no effect on glomerular volume. Furthermore, we observed no effect of insulin treatment on UAE compared to the untreated diabetic animals despite a normalization of blood glucose levels being achieved. Previous studies have shown that the diabetic state per se is followed by GH and IGF-I reduction in rats [47]. In the present study serum IGF-I was not significantly reduced in placebo-treated diabetic animals compared to the non-diabetic control rats. These observations were confirmed by the similar levels of serum IGFBP-3 in the same groups. Further, we observed no effect of octreotide on IGF-I or IGFBP-3. In early experimental diabetes circulating levels of IGFBP-1 and/or IGFBP-2 are elevated following diabetes induction [14]. This long-term experimental diabetes study is the first to demonstrate reduced levels of IGFBP-1 and/or IGFBP-2. These observations are also in contrast to clinical observations [48] and may also indicate a difference in regulation dependent on the time course of the diabetic state in rats but also on differences in species.

In conclusion, octreotide treatment has no effect on already manifest diabetic renal changes when initiated in diabetic rats after 3 to 6 months of untreated diabetes though a trend towards reduction in renal hypertrophy was observed. However, insulin treatment initiated after 6 months of untreated dia- 
betes was able to reduce the renal hypertrophy though no change in UAE was observed. This supports the hypothesis that the very early events in diabetic kidney disease with kidney IGF-I accumulation and initial rapid renal and glomerular growth are important and that treatment of diabetes and its complications must be initiated as early as possible. Further studies are needed to evaluate the role of somatostatin analogues in the treatment of diabetic kidney disease at a very early stage, and in this context determine the appropriate dose and time of treatment initiation.

Acknowledgements. This study was supported by grants from the Novo Foundation, the Nordic Insulin Foundation, the Danish Diabetes Association, the Ruth König Petersen Foundation, and the Ingeborg Maibøll Foundation, the Danish Medical Research Council. We are indebted to Ms. K. Nyborg, Ms. S. Sørensen, and Ms. K. Mathiassen for their skilled technical assistance.

\section{References}

1. Mogensen CE, Andersen MJF (1973) Increased kidney size and glomerular filtration rate in early juvenile diabetes. Diabetes 22: 706-712

2. Seyer-Hansen K (1983) Renal hypertrophy in experimental diabetes. Kidney Int 23:641-647

3. Hostetter TH, Troy JL, Brenner BM (1981) Glomerular hemodynamics in experimental diabetes. Kidney Int 19: $410-415$

4. Mogensen CE, Christensen CK (1984) Predicting diabetic nephropathy in insulin dependent patients. N Engl J Med 311: 89-93

5. Mogensen CE, Christensen CK, Christiansen JS, Boye N, Pedersen MM, Schmitz A (1988) Early hyperfiltration and late renal damage in insulin-dependent diabetes. Pediat Adolesc Endocr 17: 197-205

6. Mogensen CE (1986) Early glomerular hyperfiltration in insulin-dependent diabetics and late nephropathy. Scand J Clin Lab Invest 46: 201-206

7. Brenner BM, Hostetter TH, Olsen JL, Rennke HG, Venkatachalam MA (1981) The role of glomerular hyperfiltration in the initiation and progression of diabetic nephropathy. Acta Endocrinol (Copenh) 97: 7-10

8. Flyvbjerg A, Thorlacius-Ussing O, Naeraa R, Ingerslev J, Ørskov H (1988) Kidney tissue somatomedin C and initial renal growth in diabetic and uninephrectomized rats. Diabetologia 31: 310-314

9. Flyvbjerg A, Frystyk J, Thorlacius-Ussing O, Ørskov H (1989) Somatostatin analogue administration prevents increase in kidney somatomedin $\mathrm{C}$ and initial renal growth in diabetic and uninephrectomized rats. Diabetologia 32: 261-265

10. Flyvbjerg A, Frystyk J, Marshall SM (1990) Additive increase in kidney insulin-like growth factor I and initial renal enlargement in uninephrectomized-diabetic rats. Horm Metab Res 22: 516-520

11. Flyvbjerg A, Ørskov H (1990) Kidney tissue insulin-like growth factor I and initial renal growth in diabetic rats: relation to severity of diabetes. Acta Endocrinol (Copenh) 122: 374-378

12. Drop SLS, Brinkman A, Kortleve DJ, Groffen CAH, Schuller A, Zwarthoff EC (1991) The evolution of the insu- lin-like growth factor binding family. In: Spencer EM (ed) Modern concepts of the insulin-like growth factors, Elsevier, New York, pp 211-328

13. De Vroede MA, Tseng LY, Katsoyannis PG, Nissley SP, Rechler MM (1986) Modulation of insulinlike growth factor I binding to human fibroblast monolayer cultures by insulinlike growth factor carrier proteins released to the incubation media. J Clin Invest 77: 602-613

14. Flyvbjerg A, Kessler U, Dorka B, Funk B, Ørskov H, Kiess W (1992) Transient increase in renal insulin-like growth factor binding proteins during initial kidney hypertrophy in experimental diabetes in rats. Diabetologia 35: $589-593$

15. Flyvbjerg A, Marshall SM, Frystyk J, Hansen KW, Harris AG, Ørskov H (1992) Octreotide administration in diabetic rats: effects on renal hypertrophy and urinary albumin excretion. Kidney Int 41: 805-812

16. Serri O, Beauregard H, Brazeau P et al. (1991) Somatostatin analogue, octreotide, reduces increased glomerular filtration rate and kidney size in insulin-dependent diabetes. JAMA 265: 888-892

17. Maunsbach AB (1966) The influence of different fixatives and fixation methods on the ultrastructure of the rat kidney proximal tubule cells. II. Effects of varying osmolarity, ionic strength, buffer system and fixative concentration of glutaraldehyde solution. J Ultrastruct Res 15: 283-309

18. Gundersen HJG (1988) The new stereological tools. APMIS 96: 379-394

19. Gundersen HJG (1988) The new stereological tools. APMIS 96: 857-881

20. Boye N, Ingerslev J (1988) Rapid and inexpensive screening microdetermination of serum fructosamine results in diabetics, uraemics, and diabetics with uraemia and healthy subjects. Scand J Clin Lab Invest 48: 779-783

21. Christensen CK, Ørskov C (1984) Rapid screening PEG radioimmunoassay for quantification of pathological microalbuminuria. Diabetic Nephropathy 3: 92-94

22. D'Ercole AJ, Stiles AD, Underwood LE (1984) Tissue concentrations of somatomedin $\mathrm{C}$ : further evidence for multiple sites of synthesis and paracrine or autocrine mechanisms of action. Proc Natl Acad Sci USA 81: 935-939

23. Hossenlopp P, Seurin D, Segovia Quinson B, Hardouin S, Binoux M (1986) Analysis of serum insulin-like growth factor binding proteins using Western blotting: use of the method for titration of the binding proteins and competitive binding studies. Anal Biochem 154: 138-143

24. Flyvbjerg A, Frystyk J, Østerby R, Ørskov H (1992) Kidney IGF-I and renal hypertrophy in GH-deficient diabetic dwarf rats. Am J Physiol 262: E956-E962

25. Rasch R (1979) Prevention of diabetic glomerulopathy in streptozotocin diabetic rats by insulin treatment: Kidney size and glomerular volume. Diabetologia 16: 125-128

26. Hirschberg R, Kopple JD (1989) Evidence that insulin-like growth factor I increases renal plasma flow and glomerular filtration rate in fasted rats. J Clin Invest 83: 326-330

27. Guler H-P, Schmid C, Zapf J, Froesch ER (1989) Effects of recombinant IGF-I on insulin-secretion and renal function in normal subjects. Proc Natl Acad Sci USA 86: 2668-2872

28. Parving H-H, Noer I, Mogensen CE, Svendsen P (1978) Kidney function in normal man during short-term growth hormone infusion. Acta Endocrinol Copenh 89: 796-800

29. Christiansen JS, Gammelgaard J, Ørskov H, Anderson A, Temler S, Parving HH (1981) Kidney function and size in normal subjects before and during growth hormone administration for one week. Eur J Clin Invest 11: 487-490

30. Guler H-P, Zapf J, Scheiwiller E, Froesch ER (1988) Recombinant human insulin-like growth factor I stimulates 
growth and has distinct effects on organ size in hypophysectomized rats. Proc Natl Acad Sci USA 85: 4889-4893

31. Skottner A, Clark RG, Fryklund L, Robinson IC (1989) Growth responses in a mutant dwarf rat to human growth hormone and recombinant human insulin-like growth factor I. Endocrinology 124: 2519-2526

32. Mathews LS, Hammer RE, Behringer RR et al. (1988) Growth enhancement of transgenic mice expressing human insulin-like growth factor I. Endocrinology 123: $2827-2833$

33. Flyvbjerg A (1993) The role of insulin-like growth factor I in initial renal hypertrophy in experimental diabetes. In: Flyvbjerg A, Ørskov H, Alberti KGMM (eds) Growth hormone and insulin-like growth factor $I$ in human and experimental diabetes. John Wiley \& Sons, Chichester, pp 271306

34. Steer KA, Sochor M, Kunjara S, Doepfner W, McLean P (1988) The effect of a somatostatin analogue (SMS 201995) on the concentration of phosphoribosyl pyrophosphate and the activity of the pentose phosphate pathway in the early renal hypertrophy of experimental diabetes in the rat. Biochem Med Metab Biol 39: 226-233

35. Iwasaki S (1993) Octreotide suppresses the kidney weight and glomerular hypertrophy in diabetic rats. Nippon Jinzo Gakkai Shi 35: 247-255

36. Muntzel M, Hannedouche T, Niesor R et al. (1992) Longterm effects of a somatostatin analogue on renal hemodynamics and hypertrophy in diabetic rats. Clin Sci 83: 575581

37. Igarashi K, Nakazawa A, Tani N, Yamazaki M, Ito S, Shibata A (1991) Effect of a somatostatin analogue (SMS 201995) on renal function and excretion in diabetic rats. J Diabet Complications 5: 181-183

38. Vora J, Owens DR, Luzio SD, Atiea J, Ryder R, Hayes TM (1987) Renal response to intravenous somatostatin in insulin-dependent diabetic patients and normal subjects. J Clin Endocrinol Metab 64: 975-979

39. Pedersen MM, Christensen SE, Christiansen JS, Pedersen EB, Mogensen CE, Ørskov H (1990) Acute effects of a somatostatin analogue on kidney function in type 1 diabetic patients. Diabet Med 7: 304-309
40. Parving H-H, Christiansen JS, Noer I, Tronier B, Mogensen CE (1980) The effect of glucagon infusion on kidney function in short-term insulin-dependent juvenile diabetics. Diabetologia 19: 350-354

41. Johannesen J, Mons L, Kiil F (1977) Effect of glycine and glucagon on glomerular filtration and metabolic rates. Am J Physiol 233: F61-F66

42. Cortes P, Dulmer F, Goldman J, Levin NW (1987) Relationship between renal function and metabolic alterations in early streptozotocin-induced diabetes in rats. Diabetes 36: $80-87$

43. Almdal TP, Vilstrup H (1988) Exogenous hyperglucagonaemia in insulin controlled diabetic rats increases urea excretion and nitrogen loss from organs. Diabetologia 31: 836-841

44. Krempf M, Ranganathan S, Remy JP, Charbonnel B, Guillon J (1990) Effect of a long acting somatostatin analogue (SMS 201-995) on high glomerular filtration rate in insulin dependent diabetic patients. Int J Clin Pharmacol Ther Toxicol 28: 309-311

45. Rasch R (1980) Prevention of diabetic glomerulopathy in streptozotocin diabetic rats by insulin treatment: albumin excretion. Diabetologia 18: 413-416

46. Stackhouse S, Miller PL, Park SK, Meyer TW (1990) Reversal of glomerular hyperfiltration and renal hypertrophy by blood glucose normalization in diabetic rats. Diabetes 39: 989-995

47. Marshall SM, Alberti KGMM (1993) Alterations in the growth hormone/insulin-like growth factor I axis in human and experimental diabetes: differences and similarities. In: Flyvbjerg A, Ørskov H, Alberti KGMM (eds) Growth hormone and insulin-like growth factor I in human and experimental diabetes. John Wiley \& Sons, Chichester, pp 23-46

48. Holly JPM (1993) Insulin-like growth binding proteins in diabetic and non-diabetic states. In: Flyvbjerg A, Ørskov $\mathrm{H}$, Alberti KGMM (eds) Growth hormone and insulinlike growth factor I in human and experimental diabetes. John Wiley, Chichester, pp 47-76 